\title{
An economic analysis of community-level fast food prices and individual-level fast food intake: longitudinal effects
}

\author{
Penny Gordon-Larsen, David K. Guilkey, and Barry M. Popkin \\ Department of Nutrition, Gillings School of Global Public Health, University of North Carolina at \\ Chapel Hill, Chapel Hill, NC (PGL, BMP); Carolina Population Center, University of North \\ Carolina- Chapel Hill, Chapel Hill, NC (PGL, DKG, BMP)
}

\begin{abstract}
Background-While dietary intake is shaped by cost, there is minimal research on the association between community-level food prices and dietary intake.

Methods-We used nationally representative, longitudinal data to examine how communitylevel food price variation was associated with individual-level fast food intake by race/ethnicity and income across waves II (1996) and III (2001-02) of The National Longitudinal Study of Adolescent Health $(\mathrm{n}=11,088)$ from 158 baseline and 363 follow-up US counties.

Results-Negative binomial regression models predicting the number of fast food meals per week show strong relationships between fast food consumption and prices of fast food and soda that varied by gender and race/ethnicity. We found relatively stronger association between food prices and fast food intake for males and relatively greater price sensitivity for soda versus burgers. In the group with strongest associations (black males), a $20 \%$ increase in price of soda was associated with a decrease of a 0.25 visits to a fast food restaurant per week.
\end{abstract}

Conclusions-Economic incentives may be an effective mechanism to address fast food intake in an age group at high risk for obesity.

\section{Keywords $\left(\mathrm{MeSH}^{\star}\right)$}

diet; * adolescent; * epidemiology; * United States; economic incentives; GIS

\section{Introduction}

Food prices are increasingly a topic of interest in terms of economic strategies or incentives for healthy dietary intake. Recently, several researchers have examined the association between food prices and obesity(Chou et al., 2004, Cawley, 2004, Lakdawalla and Philipson, 2002, Powell and Chaloupka, 2009), yet these studies are largely cross-sectional and ignore direct associations with dietary intake. Others have examined cross-sectional associations between regional food prices and consumption of select foods(Darmon et al., 2003, Drewnowski and Darmon, 2005c, Cox and Wohlgenant, 1986). One recent study

(C) 2011 Elsevier Ltd. All rights reserved.

Please Address Correspondence \& Reprint Requests To: Penny Gordon-Larsen, Ph.D., University of North Carolina at Chapel Hill, Carolina Population Center, 123 West Franklin St. CB\#8120, Chapel Hill, NC 27516-3997, Phone: (W) 919-843-9966; Fax: 919-966-9159, gordon_larsen@unc.edu.

Publisher's Disclaimer: This is a PDF file of an unedited manuscript that has been accepted for publication. As a service to our customers we are providing this early version of the manuscript. The manuscript will undergo copyediting, typesetting, and review of the resulting proof before it is published in its final citable form. Please note that during the production process errors may be discovered which could affect the content, and all legal disclaimers that apply to the journal pertain. 
examined fast food prices and obesity(Powell, 2009) and another recent study investigated the association between food prices with energy intake, weight, and diabetes risk over a 20year period(Duffey et al., 2010).

Yet there has been minimal research linking community-level food prices to individual-level dietary behaviors and overall food consumption patterns. The earlier USDA surveys as well as the National Health and Nutrition Examination Survey do not allow food price data to be linked to individual level data at small geographic levels (e.g., many deal with state-level prices). Yet, data from experimental studies show that food price is one of the most influential factors in determining food choice, second only to taste(Shannon et al., 2002, Glanz et al., 1998, French, 2003, Epstein et al., 2006, Epstein et al., 2007).

Further, there is a large agricultural economics literature that addresses the association between food price data with dietary behavior, food production, and overall food expenditure and consumption, yet this work is focused on commodity- and brand-level demand(Frazao, 1999, Timmer et al., 1984). Of particular relevance is the differential association between food prices and dietary intake across income levels as individuals of low income are typically more sensitive to changes in food price(Chung and Myers, 1999a, MacDonald and Nelson Jr., 1991, Stewart et al., 2004, Stewart et al., 2003, Popkin, 2008a) and tend to have less varied, lower quality diets compared to higher income consumers(Hulshof et al., 2003). A range of small studies suggest that food expenditure patterns for high-priced healthier products is associated with reductions in fruit, vegetable, and dairy consumption among low income families(Chung and Myers, 1999b, Kirkpatrick and Tarasuk, 2003, Guo et al., 1999). However, there are still major gaps in the literature and a recent review called for studies estimating price effects and responsiveness among at risk populations, particularly low-income and ethnic minority populations.(Andreyeva et al., 2009)

This study capitalizes on data from a large, ethnically diverse and nationally representative longitudinal cohort across the age period between adolescence and young adulthood, a period of heightened risk for obesity incidence(Gordon-Larsen et al., 2004). Individual-level survey data were spatially and temporally linked to community food price data at the county level from the Council for Community and Economic Research, a resource widely used in studies of cigarette prices and tobacco consumption(Chaloupka et al., 2002, Grossman and Chaloupka, 1997, Liang et al., 2003, Grossman, 1989, Young and Bielinska-Kwapisz, 2003) and associations between community-level prices of select foods and related individual-level dietary consumption of fast foods were estimated with attention to variation by race/ ethnicity and income.

\section{Methods}

\section{Study Population}

Data are from waves II (1996) and III (2001-02) of The National Longitudinal Study of Adolescent Health (Add Health), a cohort study of 20,745 adolescents representative of the U.S. school-based population in grades 7 to 12 (11-22 years of age) in 1994-95 followed into wave II (12-22 years) and wave III (18-28 years). Add Health included a core sample plus subsamples of selected minority and other groupings collected under protocols approved by the Institutional Review Board at the University of North Carolina at Chapel Hill. The survey design and sampling frame, which includes following the school-aged population at waves I and II and the full baseline sample at wave III have been discussed elsewhere(Gordon-Larsen et al., 1999, Miller et al., 2004). A Geographic Information System (GIS) was used to link time-varying community-level data at the county-level to Add Health respondent residential locations at each wave as reported elsewhere(Boone- 
Heinonen et al., 2010a). Respondent residential locations were linked to attributes from time-matched price data (described below), which were merged with individual-level Add Health interview responses. We include measures from 18,405 unique individuals seen at one or both waves II and III (16,604 in wave II, 14,569 in wave III), with a total of 11,088 who were seen at both waves II and III. Data are available at the census tract level, which average approximately 4,000 inhabitants and are designed to be relatively homogeneous in terms of population characteristics. Data are also available at the county level, a county is a geographic subdivision of a state that is generally assigned governmental authority. In the US, the average number of counties per state is 62 . These geographic coverage increases over time from baseline counties [ $\mathrm{N}=158]$ and tracts [ $\mathrm{N}=850]$ into follow up counties $[\mathrm{N}=363]$ and tracts [ $\mathrm{N}=2714]$. The average number of respondents per county was 131.3 at wave I and 133.3 at wave III.

\section{County-Level Food prices}

County-level food price data were compiled by, and downloaded from, the Council for Community and Economic Research (C2ER, formerly the American Chamber of Commerce Research Association). Conducted quarterly for approximately 300 US communities, this survey provides price levels for more than 60 consumer goods and services across participating metropolitan and nonmetropolitan areas. The C2ER data represent the most comprehensive national community-level food price data available and have been used widely in studies of tobacco pricing and smoking behavior(Chaloupka et al., 2002, Grossman and Chaloupka, 1997). Grocery items (i.e., specific foods, beverages), fast food items, cost of living and overall price indices, and cigarette prices have been collected as part of the Inter-City Cost of Living Index, published quarterly since 1968 for 300 US cities(Christian and Rashad, 2009). For cities across the country, prices are collected for a variety of goods and services, including grocery prices, average utility costs, health care, and miscellaneous items such as the price of a haircut or cost of dry cleaning. From the available price data, we used: soda (cost for a 2 Liter (L) bottle) and hamburger (1.4 pound (lb) burger, purchased away-from-home) since these foods are related to fast food intake. We also include the consumer price index (CPI) as a control measure. The CPI represents changes in prices of all goods and services purchased for consumption by urban households, including user fees and sales and excise taxes, but excluding income taxes(Gordon-Larsen et al., 2009). The overall CPI is typically preferred to food specific CPI values because it controls for total cost of living(Christian and Rashad, 2009, Duffey et al., 2008). The mean CPI across all analytical communities was 1.86 at baseline (1996) and 1.78 at follow-up (2001), which is interpreted in relative terms of a one-dollar purchase at the index base period (1982-84) versus at each study period: 1996: \$1.86 and 2001: \$1.78. Given that we follow individuals over time regardless of residential movement and a portion of the sample moves residences over time, some of the changes in prices simply reflect changes in community of residence over time, rather than true declines in prices (the number of countries represented more than doubled between wave II and wave III). However, there is evidence of variation in food prices over time, with disproportionate stability of specific types of foods, such as carbonated drinks, fats and oils, and sugar and sweets, while prices of fresh fruits and vegetables have had a steep increase over the past two decades in the US(Popkin, 2011) .

We also include a selection of prices of hypothesized complimentary and substitution (replacement) foods and beverages, which differ based on the food being examined, and include: whole milk (cost for one-half gallon), pizza (12-13 inch cheese, thin crust purchased away-fromhome), steak (cost of $1 \mathrm{lb}$., USDA choice), and fried chicken (cost of 2 pieces, thigh and drumstick, purchased away-from-home). We use these complimentary and 
substitution food price data as control variables in the models. In addition, we include the consumer price index as another price control in statistical models.

All prices were expressed in real terms using 2006, quarter 3 (index $=100 \%$ ) as the baseline. The C2ER price data were linked to Add Health respondents temporally (based on the year and quarter of Add Health exam dates) and spatially at the county level (based on the respondent's residential location at each time point). For respondents for whom there was not a direct match between residential location, C2ER county, and year in which food price data were collected, prices were imputed (6,344 observations, 30\%) using food price data at larger aggregate level (county-averaged C2ER values in counties with more than one C2ER centroid) and adjacent quarter using a method that takes into account spatial and temporal missing data and has been published widely(Duffey et al., 2010, Chou et al., 2004, Grossman, 1989, Grossman and Chaloupka, 1997, Raper, 1999). For example, if a respondent's residential location had a single matching county indicator code and price data were available for the year and quarter in which the respondent was surveyed, prices from that matching county were assigned to the respondent. Model-based tests of statistical significance of imputed price data showed no statistical difference based on imputed versus non-imputed price data, thus both were retained in the final models.

\section{Individual-level self-reported behaviors and sociodemographics}

Consumption of fast food was quantified from participant responses to the following question at waves II and III: In the last seven days, on how many days did you eat at a fast food type place-McDonalds, Kentucky Fried Chicken, Pizza Hut, Taco Bell, or a local fast food restaurant? Response categories ranged from 0 to 7 times per week, calculated to reflect a per-week frequency.

Individual-level sociodemographic control variables included wave I self-identified race (white, black, Asian, Hispanic based on primary race/ethnicity reported by respondents and their parents), parent-reported annual household income and highest education attained (<high school, high school or GED, some college, $\geq$ college degree), indicator variables representing the school sampled as part of the original Add Health sampling frame (145 indicator variables), and age at wave II and III interviews.

\section{Statistical Methods}

All analyses were done using Stata 10 (Stata Corp, College Station, TX). Descriptive statistics for food prices, and reported frequency of fast food meals consumed per week were compared across the two exam periods, with statistical significance set at the $p<0.05$ level (two-tailed test).

Add Health was a school-based sample, so the respondents' school at wave I is the most important source of clustering. After wave I, individuals can move to other communities but we retain original school level dummies in the models for subsequent waves. The hypothesis is that the school dummies capture long lasting unobservable influences on individual decisions even after the individual leaves their place of residence at wave I. The boundaries of the school catchment areas do not correspond with the county boundaries, so schools and county units do not provide a hierarchical structure (e.g., students nested within schools, schools nested within counties) required for multi-level models. Furthermore, since Add Health was a school-based sample (school catchment areas vary greatly across states) rather than sampled based on census units, counties contained few respondents on average (sparse data), with vastly different numbers of respondents across counties (unbalanced). For example, at both waves I and III, approximately $40 \%$ of counties had 5 or fewer respondents, whereras at wave I $29 \%$ of counties had 200 or more respondents and at wave 
III $5 \%$ of counties had 200 or more respondents. For these reasons, we do not use multilevel models, but we do correct for school-level clustering using school-level indicator variables in the models.

Since the dependent variable in the regression model is a count of the number of individuallevel fast food meals in a week, an extension of the Poisson model rather than ordinary least squares was used as an estimation method. It is well known that in the Poisson model is specifically designed to deal with dependent variables such as this. However, a shortcoming of the Poisson model is that the mean and variance of the outcome variable are assumed to be the same - this is the equidisperson property of the model. Since this assumption is quite restrictive, the negative binomial model, a continuous mixture model that extends the Poisson model by allowing unobserved heterogeneity so that the mean and variance are separate parameters to be estimated, was used. The negative binomial model assumes that the mixing distribution follows a gamma distribution with parameter $\alpha$. When $\alpha$ is equal to zero, the negative binomial simplifies to the Poisson model. However, in this case the null was rejected at $\alpha=0$ for $\mathrm{p}<0.05$.

In addition to testing for simplification to a Poisson model, there was the possibility that bias could be introduced if unobserved factors that affect fast food consumption were correlated with neighborhood choice and school choice. If this was true, community characteristics including prices in the community could be correlated with the error term. To correct for this bias, school level indicator variables were included in the model. A Hausman style test was used to test whether or not it was necessary to include the school dummies to correct for bias and the null hypothesis that they were not necessary was rejected at $\mathrm{p}<0.05$.

We also tested whether having fast food restaurants in the community influenced the effect of community-level food prices on individual-level fast food consumption. To test this effect, we entered a variable representing the availability of fast food restaurants within 3 $\mathrm{km}$ of each respondent's residential location. These data were obtained from a commercial dataset of U.S. businesses. Fast food restaurants include a wide range of quick service establishments providing generally premade food and little table service; they include traditional burger outlets as well as delicatessens and coffee shops. To capture a more homogenous, well-defined category, we examined only chain fast food restaurants (e.g., McDonald's or Pizza Hut), classified according to the 8-digit Standard Industrial Classification (SIC) code 58120307 (fast-food restaurant, chain). We determined counts of fast food restaurants within $3 \mathrm{~km}$ from each respondent's residential address (network buffer), based on empirical rationale for similar neighborhood resource data.(BooneHeinonen et al., 2010b, Boone-Heinonen et al., 2011) We found these additional community-level controls did not add to the explanatory power of the model and thus they were not included in final models.

We hypothesized differential price effects by race/ethnicity and by income. Sensitivity testing for the model with and without interaction terms yielded a chi-squared statistic of 155.95 with 36 degrees of freedom, $\mathrm{p}<0.0001$, thus indicating that the interaction terms as a group were highly significant. Thus, the final model specification included interaction terms for food price by race/ethnicity and food price by income. Since the model with interaction terms was nonlinear and somewhat difficult to interpret, simulation methods were used to examine the estimated effects of price changes. The simulation provides illustration of variation in race and income group across estimated effects of price. 


\section{Results}

This nationally representative and ethnically diverse sample provides substantial variation across parental income levels (Table 1). The mean number of individual-level reported fast food meals per week increased from wave II to III, while the community-level mean price of burgers and particularly sodas for the locations where our sample lived declined over time.

Negative binomial models predicting the number of fast food meals per week show statistically greater intake among males than females, and significantly lower intake for Asians, Hispanics and non-Hispanic blacks relative to whites (Table 2) even after controlling for wave, age, and community. Further there were differential relationships between community-level food prices of our key target foods, soda and burgers and individual-level fast food intake across race/ethnic groups and by income.

To aid interpretation of results for our key findings (burger and soda), Figure 1 shows predictions based on the model coefficients from Table 2 . The relatively stronger association between community-level food prices and individual-level fast food intake for males relative to females is clearly evident. For example, in the group with strongest associations (black males), we found a $20 \%$ increase in price of soda was associated with a decrease of a 0.25 visits to a fast food restaurant per week.

Further, there is variation in the association by food type and across race/ethnicity, with greatest association between food prices and fast food intake observed for price of soda in black males.

Figure 2 shows another set of predictions based on the model coefficients for our key findings (burger and soda) from Table 2. Again there is race/ethnic variation in the association between community-level food prices and individual-level fast food intake that differ across food type. In addition, there was variation across income, with greater price sensitivity for community-level soda versus burger prices. Further, there was relatively greater inverse change in individual-level fast food intake with income, such that bigger changes in individual-level fast food intake were seen at low income level, with greatest association in blacks

\section{DISCUSSION}

Using nationally representative, longitudinal data, the association between community-level food price and individual-level fast food intake was estimated, with focus on variation by race/ethnicity and income. Increases in community-level prices of fast food and soda were associated with reductions in individual-level fast food consumption. Further, there were relatively stronger associations between community-level food prices and individual-level fast food intake for males and relatively greater price sensitivity for soda versus burgers. On average, our findings suggest that a $20 \%$ increase in soda price was associated with a reduction of approximately one-quarter visits to a fast food restaurant per week. This type of reduction could potentially have a substantial impact at the population level.

A recent review suggests that away-from-home foods and sodas are among the most responsive to price changes(Andreyeva et al., 2009), which is confirmed in the present study. In general, the current literature has largely included cross-sectional, descriptive analyses of ecological variations in income, energy-density of diet, and obesity(Maillot et al., 2007, Drewnowski and Darmon, 2005b, Drewnowski and Specter, 2004). Thus, few studies have examined food prices and how they might underlie health disparities. In fact, a recent review called for studies estimating price effects and responsiveness among at risk populations.(Andreyeva et al., 2009) The current research demonstrates variation in price 
sensitivity across race/ethnicity and income, with greater price sensitivity for soda versus burger prices and relatively higher change in individual-level fast food intake with community-level soda prices for blacks. A similar relationship was found among adults followed 20 years over the 20-34 to 40-54 age period(Duffey et al., 2010). Further, there seems to be greater price sensitivity for soda for individuals of low income and an intervention study suggests responsivity to soda price manipulation.(Block et al., 2010) In contrast, Powell(Powell, 2009, Powell et al., 2010) using longitudinal, self-reported height and weight data (but no data on fast food intake) found no such association between fast food prices and obesity.

Given higher prices of healthy foods (i.e. fresh fruits and vegetables)(Drewnowski and Darmon, 2005a, Drewnowski and Darmon, 2005d), public health professionals, politicians and others have suggested that foods high in calories, saturated fat, or added sugar be subject to added taxes and/or that healthier foods be subsidized(Cash et al., 2005, Chouinard et al., 2007, Jacobson and Brownell, 2000, Popkin, 2008a). Such manipulation of food prices, through subsidies and other methods, has been a mainstay of global agricultural and food policy(Popkin, 2008b, von Braun, 2008) employed as a means to increase availability of animal foods and basic commodities, but have not been readily employed as a mechanism to promote public health and chronic disease prevention efforts.(Popkin, 2008b, WHO, 2000, WHO/FAO, 2003) The current results suggest that increased soda prices may have associated decreases in fast food intake. While the size of the estimated impact of shifts in community-level prices on individual-level fast food consumption is relatively low, at the aggregate level, shifts in one or more meals eaten away from home at fast food establishments per week translates to significant impact on daily caloric intake as well as many important minerals(Guthrie et al., 2002, Paeratakul et al., 2003).

While other studies have examined the association between consumption of away-fromhome foods, such as fast food intake, and adverse health outcomes(Duffey et al., 2007, Popkin et al., 2005, Prentice and Jebb, 2003, Burdette and Whitaker, 2004, Currie et al., 2009, Duffey et al., 2009), these studies generally ignore self-selection of fast food eating behaviors as well as consumption of other related food substitutions. In this study, we estimate the effect of community-level prices on individual-level fast food consumption. While, we face the issue of self-selection from the point of residential selection, we control for this with our use of indicator variables for school.

While major strengths of this study include our ability to address differential associations by race/ethnicity and income, the current analysis is limited by its focus on a small number of food and beverage groups - albeit the most important foods in terms of price sensitivity(Andreyeva et al., 2009). Additional and important substitution and complementary foods and beverages may exist and should be examined in future studies. The relationship between community-level price and individual-level consumption of "healthy" food items (i.e. raw fruits and vegetables) should also be examined; the C2ER price data do not include full detail on such foods. Ideally, the current research would benefit from inclusion of a full set of prices and food groups, as would the use of the demand approach frequently employed by economists, the Almost Ideal Demand System(Huang, 1997, Huang and Bouis, 1996, Wu et al., 1995). It is also possible that some of these paired changes, i.e. the price and consumption of soda, are parallel trends over time which are associated with other unobserved factors, and are not necessarily related. There are also limitations in the C2ER data. First, the C2ER price data are available at participating metropolitan and nonmetropolitan areas; these data sources provide the only current and historical price data available at the smallest geographic unit in the US. While these price data are only available for larger county-level units, it is possible that withincounty price variations are important, however there are no national food price datasets at 
smaller than county level. Further, there is no way to obtain retrospective price data other than the C2ER data. Given that we follow individuals over time regardless of residential movement and a portion of the sample moves residences over time, some of the changes in prices may reflect changes in community of residence over time, rather than true decreases in prices (note that the number of counties where respondents lived doubled between waves II and III). As such, our analysis is individual-based in that we estimate the effect of community-level food prices on individual-level behavior, as opposed to following specific communities over time. There are simply no national, community-level, longitudinal samples with food price and individual-level behavior data. Our findings have clear implications for how food prices influence individual behavior. There is a clear need for longitudinal, national research in this area, and currently the C2ER data provide the only option. Yet even so, the datasets include some missing temporal and geographic data. In the current study this limitation was overcome by using imputation strategies widely used in the literature(Grossman and Chaloupka, 1997, Grossman, 1989, Chou et al., 2004, Duffey et al., 2010, Raper, 1999). We are also limited by the choice of data collected by the C2ER. Whereas the price of soda is reported per 2-liter size, this size is not the usual size to be purchased at fast food restaurants. Nonetheless, the pricing of soda will still impact the relative price of soda regardless of purchase size. It is also possible for some degree of county mismatch in individuals who moved residences shortly before measurement.

In sum, using national, longitudinal data including community-level food prices, observed increases in community-level prices of fast food and soda were associated with reductions in individual-level fast food consumption. Further, there was variation in these associations by race/ethnicity and income, with generally greater price sensitivity for soda versus burgers. The current findings contribute to the recent national discussion regarding economic incentives for reducing obesity(Brownell and Frieden, 2009).

Research Highlights

1. There are few longitudinal studies that link community-level food prices with dietary intake

2. Prices of fast food were inversely associated with fast food intake

3. Price sensitivity varied by gender and race/ethnicity

4. Economic incentives may be an effective mechanism to address fast food intake

\section{Supplementary Material}

Refer to Web version on PubMed Central for supplementary material.

\section{Acknowledgments}

This research was funded by National Institutes of Health R01HD057194, R01 HD041375, R01 HD39183, and a cooperative agreement with the Centers for Disease Control and Prevention (CDC SIP No. 5-00). The authors were supported by the Carolina Population Center (the R24 Center grant from NIH): 5 R24 HD050924 from the Eunice Kennedy Shriver National Institute of Child Health and Human Development (NICHD). This research uses data from Add Health, a program project directed by Kathleen Mullan Harris PhD and designed by J. Richard Udry $\mathrm{PhD}$, Peter S. Bearman PhD, and Kathleen Mullan Harris PhD at the University of North Carolina at Chapel Hill, and funded by grant P01-HD31921 from the Eunice Kennedy Shriver National Institute of Child Health and Human Development, with cooperative funding from 23 other federal agencies and foundations. Special acknowledgment is due Ronald R. Rindfuss PhD and Barbara Entwisle PhD both from the University of North Carolina at Chapel Hill for assistance in the original design. Information on how to obtain the Add Health data files is available on the Add Health website http://www.cpc.unc.edu/addhealth). No direct support was received from grant P01-HD31921 for this analysis. None of the acknowledged individuals received compensation for their assistance. 


\section{References Cited}

Andreyeva T, Long MW, Brownell KD. The Impact of Food Prices on Consumption: A Systematic Review of Research on the Price Elasticity of Demand for Food. Am J Public Health. 2009; 100:216-222. [PubMed: 20019319]

Block JP, Chandra A, Mcmanus KD, Willett WC. Point-of-purchase price and education intervention to reduce consumption of sugary soft drinks. Am J Public Health. 2010; 100:1427-1433. [PubMed: 20558801]

Boone-Heinonen J, Diez Roux AV, Kiefe CI, Lewis CE, Guilkey DK, Gordon-Larsen P. Neighborhood socioeconomic status predictors of physical activity through young to middle adulthood: the CARDIA study. Soc Sci Med. 2011; 72:641-649. [PubMed: 21316829]

Boone-Heinonen J, Evenson KR, Song Y, Gordon-Larsen P. Built and socioeconomic environments: patterning and associations with physical activity in U.S. adolescents. Int J Behav Nutr Phys Act. 2010a; 7:45. [PubMed: 20487564]

Boone-Heinonen J, Popkin BM, Song Y, Gordon-Larsen P. What neighborhood area captures built environment features related to adolescent physical activity? Health \& Place. 2010b; 16:1280-1286. [PubMed: 20650673]

Brownell KD, Frieden TR. Ounces of Prevention -- The Public Policy Case for Taxes on Sugared Beverages. N Engl J Med. 2009 NEJMp0902392.

Burdette HL, Whitaker RC. Neighborhood playgrounds, fast food restaurants, and crime: relationships to overweight in low-income preschool children. Prev Med. 2004; 38:57-63. [PubMed: 14672642]

Cash S, Sunding D, Zilberman D. Fat taxes and thin subsidies: Prices, diet, and health outcomes. Acta Agriculturae Scandinavica, Section C - Economy. 2005; 2:167-174. (8).

Cawley J. An economic framework for understanding physical activity and eating behaviors. American Journal of Preventive Medicine. 2004; 27:117-125. [PubMed: 15450622]

Chaloupka FJ, Cummings KM, Morley CP, Horan JK. Tax, price and cigarette smoking: evidence from the tobacco documents and implications for tobacco company marketing strategies. Tob Control. 2002; 11 Suppl 1:I62-I72. [PubMed: 11893816]

Chou SY, Grossman M, Saffer H. An economic analysis of adult obesity: results from the Behavioral Risk Factor Surveillance System. J Health Econ. 2004; 23:565-587. [PubMed: 15120471]

Chouinard H, Davis D, Lafrance J, Perloff J. Fat Taxes: Big Money for Small Change. Fat Taxes: Big Money for Small Change. 2007; 10:1-30. (article 2).

Christian T, Rashad I. Trends in U.S. food prices, 1950-2007. Econ Hum Biol. 2009; 7:113-120. [PubMed: 19091636]

Chung C, Myers S. Do the poor pay more for food? An analysis of grocery store availability and food price disparities. J Consumer Affairs. 1999; 33:276-296.

Cox TL, Wohlgenant MK. Prices and Quality Effects in Cross-Sectional Demand Analysis. American Journal of Agricultural Economics. 1986; 68:908-919.

Currie J, Dellavigna S, Moretti E, Pathania V. The effect of fast food restaurants on obesity. NBER Working Paper No. 14721. 2009

Darmon N, Ferguson E, Briend A. Do economic constraints encourage the selection of energy dense diets? Appetite. 2003; 41:315-322. [PubMed: 14637330]

Drewnowski A, Darmon N. The economics of obesity: dietary energy density and energy cost. Am J Clin Nutr. 2005a; 82:265S-273S. [PubMed: 16002835]

Drewnowski A, Darmon N. Food Choices and Diet Costs: an Economic Analysis. J. Nutr. 2005c; 135:900-904. [PubMed: 15795456]

Drewnowski A, Specter SE. Poverty and obesity: the role of energy density and energy costs. Am J Clin Nutr. 2004; 79:6-16. [PubMed: 14684391]

Duffey KJ, Gordon-Larsen P, Ayala GX, Popkin BM. Birthplace is associated with more adverse dietary profiles for US-born than for foreign-born Latino adults. J Nutr. 2008; 138:2428-2435. [PubMed: 19022968]

Duffey KJ, Gordon-Larsen P, Jacobs DRJ, Williams OD, Popkin BM. Differential associations of fast food and restaurant food consumption with $3-\mathrm{y}$ change in body mass index: the Coronary Artery 
Risk Development in Young Adults Study. Am J Clin Nutr. 2007; 85:201-208. [PubMed: 17209197]

Duffey KJ, Gordon-Larsen P, Shikany JM, Guilkey D, Jacobs DR Jr, Popkin BM. Food price and diet and health outcomes: 20 Years of the CARDIA Study. Arch Intern Med. 2010; 170:420-426. [PubMed: 20212177]

Duffey KJ, Gordon-Larsen P, Steffen LM, Jacobs DR Jr, Popkin BM. Regular Consumption from Fast Food Establishments Relative to other Restaurants is Differentially Associated with Metabolic Outcomes in Young Adults. J. Nutr. 2009; 139:2113-2118. [PubMed: 19776183]

Epstein LH, Dearing KK, Paluch RA, Roemmich JN, Cho D. Price and maternal obesity influence purchasing of low- and high-energy-dense foods. Am J Clin Nutr. 2007; 86:914-922. [PubMed: 17921365]

Epstein LH, Handley EA, Dearing KK, Cho DD, Roemmich JN, Paluch RA, Raja S, Pak Y, Spring B. Purchases of Food in Youth. Influence of Price and Income. Psychological Science. 2006; 17:8289. [PubMed: 16371148]

Frazao, E. America's Eating Habits: Changes and Consequences. Washington, DC: USDA; 1999.

French SA. Pricing effects on food choices. J Nutr. 2003; 133:841S-843S. [PubMed: 12612165]

Glanz K, Basil M, Maibach E, Goldberg J, Snyder D. Why Americans eat what they do: taste, nutrition, cost, convenience, and weight control concerns as influences on food consumption. $\mathrm{J}$ Am Diet Assoc. 1998; 98:1118-1126. [PubMed: 9787717]

Gordon-Larsen P, Adair LS, Nelson MC, Popkin BM. Five-year obesity incidence in the transition period between adolescence and adulthood: the National Longitudinal Study of Adolescent Health. Am J Clin Nutr. 2004; 80:569-575. [PubMed: 15321794]

Gordon-Larsen P, Hou N, Sidney S, Sternfeld B, Lewis CE, Jacobs DR Jr, Popkin BM. Fifteen-year longitudinal trends in walking patterns and their impact on weight change. Am J Clin Nutr. 2009; 89:19-26. [PubMed: 19056560]

Gordon-Larsen P, Mcmurray RG, Popkin BM. Adolescent physical activity and inactivity vary by ethnicity: The National Longitudinal Study of Adolescent Health. J Pediatr. 1999; 135:301-306. [PubMed: 10484793]

Grossman M. Health benefits of increases in alcohol and cigarette taxes. Br J Addict. 1989; 84:11931204. [PubMed: 2684304]

Grossman M, Chaloupka FJ. Cigarette taxes. The straw to break the camel's back. Public Health Rep. 1997; 112:290-297. [PubMed: 9258294]

Guo X, Popkin B, Mroz T, Zhai F. Food price policy can favorably alter macronutrient intake in China. J Nutr. 1999; 129:994-1001. [PubMed: 10222391]

Guthrie JF, Lin BH, Frazao E. Role of food prepared away from home in the American diet, 1977-78 versus 1994-96: changes and consequences. J Nutr Educ Behav. 2002; 34:140-150. [PubMed: 12047838]

Huang, K.; Bouis, H. Structural changes in the Demand for Food in Asia” Food, Agriculture and the Environment discussion paper 11. Washington DC: International Food Policy Research Institute; 1996.

Huang KS. Nutrient Elasticities in a complete food demand system. Am J Agric Econ. 1997; 78:2129.

Hulshof KF, Brussaard JH, Kruizinga AG, Telman J, Lowik MR. Socio-economic status, dietary intake and 10 y trends: the Dutch National Food Consumption Survey. Eur J Clin Nutr. 2003; 57:128-137. [PubMed: 12548307]

Jacobson M, Brownell K. Small Taxes on Soft Drinks and Snack Foods to Promote Health. Am J Public Health. 2000; 90:854-857. [PubMed: 10846500]

Kirkpatrick S, Tarasuk V. The relationship between low income and household food expenditure patterns in Canada. Public Health Nutr. 2003; 6:589-597. [PubMed: 14690040]

Lakdawalla, D.; Philipson, T. NBER Working Paper no. 8946. Cambridge, MA: National Bureau of Economic Research; 2002. The growth of obesity and technological change: A theoretical and empirical examination.

Liang L, Chaloupka F, Nichter M, Clayton R. Prices, policies and youth smoking, May 2001. Addiction. 2003; 98 Suppl 1:105-122. [PubMed: 12752364] 
Macdonald JM, Nelson P Jr. Do the poor still pay more? Food price variations in large metropolitan areas. Journal of Urban Economics. 1991; 30:344-359.

Maillot M, Darmon N, Darmon M, Lafay L, Drewnowski A. Nutrient-dense food groups have high energy costs: an econometric approach to nutrient profiling. J Nutr. 2007; 137:1815-1820. [PubMed: 17585036]

Miller WC, Ford CA, Morris M, Handcock MS, Schmitz JL, Hobbs MM, Cohen MS, Harris KM, Udry JR. Prevalence of chlamydial and gonococcal infections among young adults in the United States. JAMA. 2004; 291:2229-2236. [PubMed: 15138245]

Paeratakul S, Ferdinand DP, Champagne CM, Ryan DH, Bray GA. Fast-food consumption among US adults and children: dietary and nutrient intake profile. J Am Diet Assoc. 2003; 103:1332-1338. [PubMed: 14520253]

Popkin, BM. The World Is Fat--The Fads, Trends, Policies, and Products That Are Fattening the Human Race. New York: Avery-Penguin Group; 2008.

Popkin BM. Agricultural policies, food and public health. EMBO reports. 2011; 12:11-18. [PubMed: 21151043]

Popkin BM, Duffey K, Gordon-Larsen P. Environmental influences on food choice, physical activity and energy balance. Physiol Behav. 2005; 86:603-613. [PubMed: 16246381]

Powell LM. Fast food costs and adolescent body mass index: Evidence from panel data. Journal of Health Economics. 2009; 28:963-970. [PubMed: 19732982]

Powell LM, Chaloupka FJ. Food prices and obesity: evidence and policy implications for taxes and subsidies. Milbank Q. 2009; 87:229-257. [PubMed: 19298422]

Powell LM, Han E, Chaloupka FJ. Economic contextual factors, food consumption, and obesity among U.S. adolescents. J Nutr. 2010; 140:1175-1180. [PubMed: 20392882]

Prentice AM, Jebb SA. Fast foods, energy density and obesity: a possible mechanistic link. Obes Rev. 2003; 4:187-194. [PubMed: 14649369]

Raper M. Self-Selection Bias and Cost-of-Living Estimates. Journal of Economics and Finance. 1999; 23:64-77.

Shannon C, Story M, Fulkerson JA, French SA. Factors in the school cafeteria influencing food choices by high school students. J Sch Health. 2002; 72:229-234. [PubMed: 12212407]

Stewart H, Blisard N, Bhuyan S, Naya R. The Demand for Food Away From Home: Full Service or Fast Food? U.S. Department of Agriculture Economic Research Services. 2004

Stewart H, Blisard N, Jolliffe D. Do Income Constraints Inhibit Spending on Fruits and Vegetables Among Low-Income Households? Journal of Agricultural and Resource Economics. 2003; 28:465-480.

Timmer, CP.; Falcon, WP.; Pearson, SR. Food policy analysis. Baltimore: The Johns Hopkins University Press for the World Bank; 1984.

Von Braun, J.; Ahmed; Akhter; Asenso-Okyere; Kwadwo; Fan; Shenggen; Gulati; Ashok; Hoddinott; John; Pandya-Lorch; Rajul; Rosegrant; Mark, W.; Ruel; Marie; Torero; Maximo; Van Rheenen; Teunisand; Von Grebmer; Klaus. High Food Prices: The What, Who, and How of Proposed Policy Actions. In: IFPRI. , editor. Policy Brief. Washington DC: IFPRI; 2008.

WHO. Obesity: preventing and managing the global epidemic. Report of a WHO consultation. World Health Organ Tech Rep Ser. 2000.

WHO/FAO. Expert Consultation on Diet, Nutrition and the Prevention of Chronic DiseasesReport of the joint WHO/FAO expert consultation. Geneva: World Health Organization; 2003.

$\mathrm{Wu}$ Y, Li E, Samuel N. Food consumption in urban China: an empirical analysis. Applied Economics. 1995; v27:509. (7).

Young DJ, Bielinska-Kwapisz A. Alcohol consumption, beverage prices and measurement error. J Stud Alcohol. 2003; 64:235-238. [PubMed: 12713197] 
Males

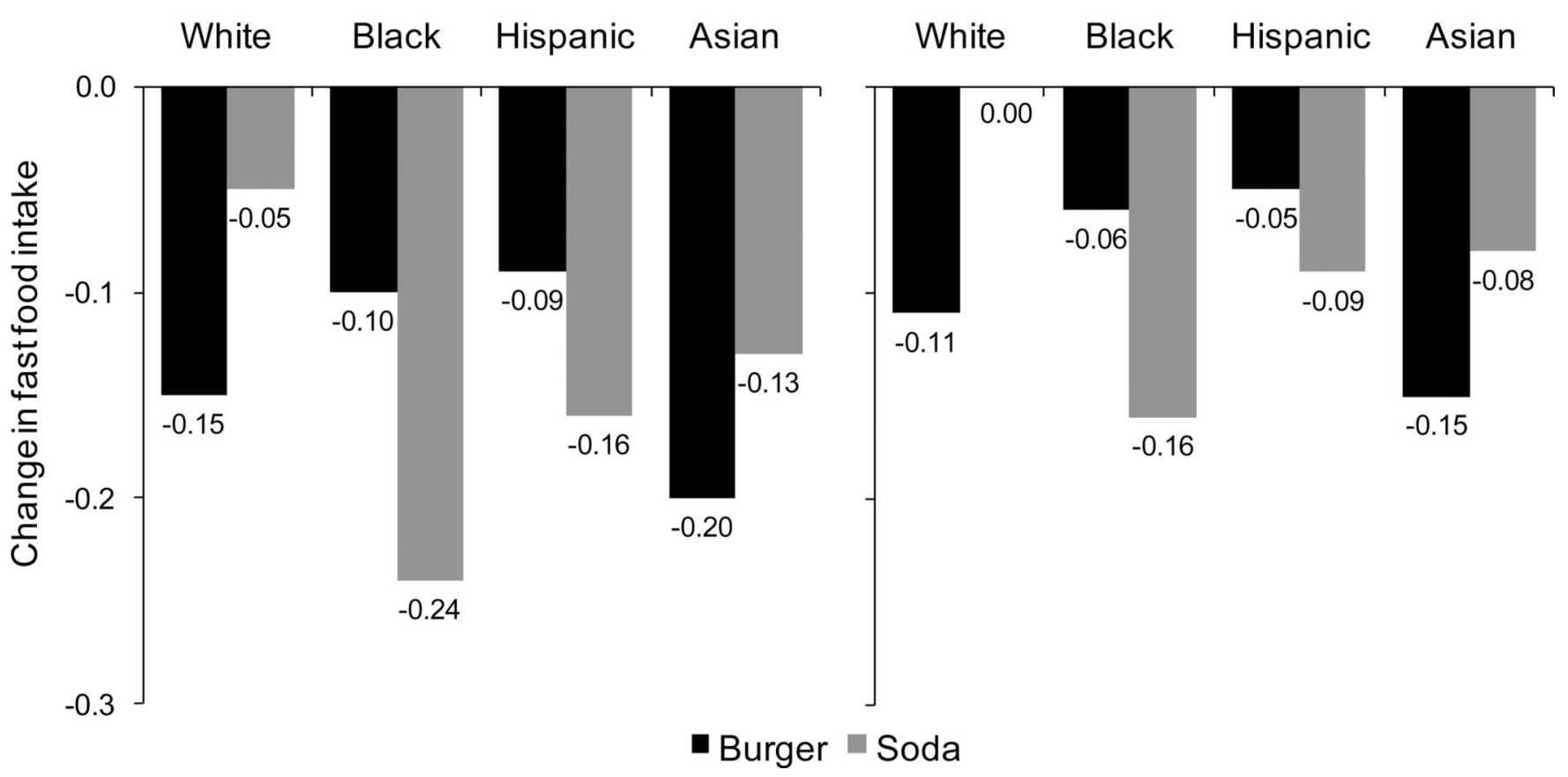

Figure 1.

Twenty percent increase in County-level prices of soda and burgers and associated decrease in number of individual-level fast food eating occasions by individual-level gender and race, The National Longitudinal Study of Adolescent Health waves II (1996, 12-22 years) and III (2001, 18-28 years) 
Burger

White

Asian

White

\section{Soda}

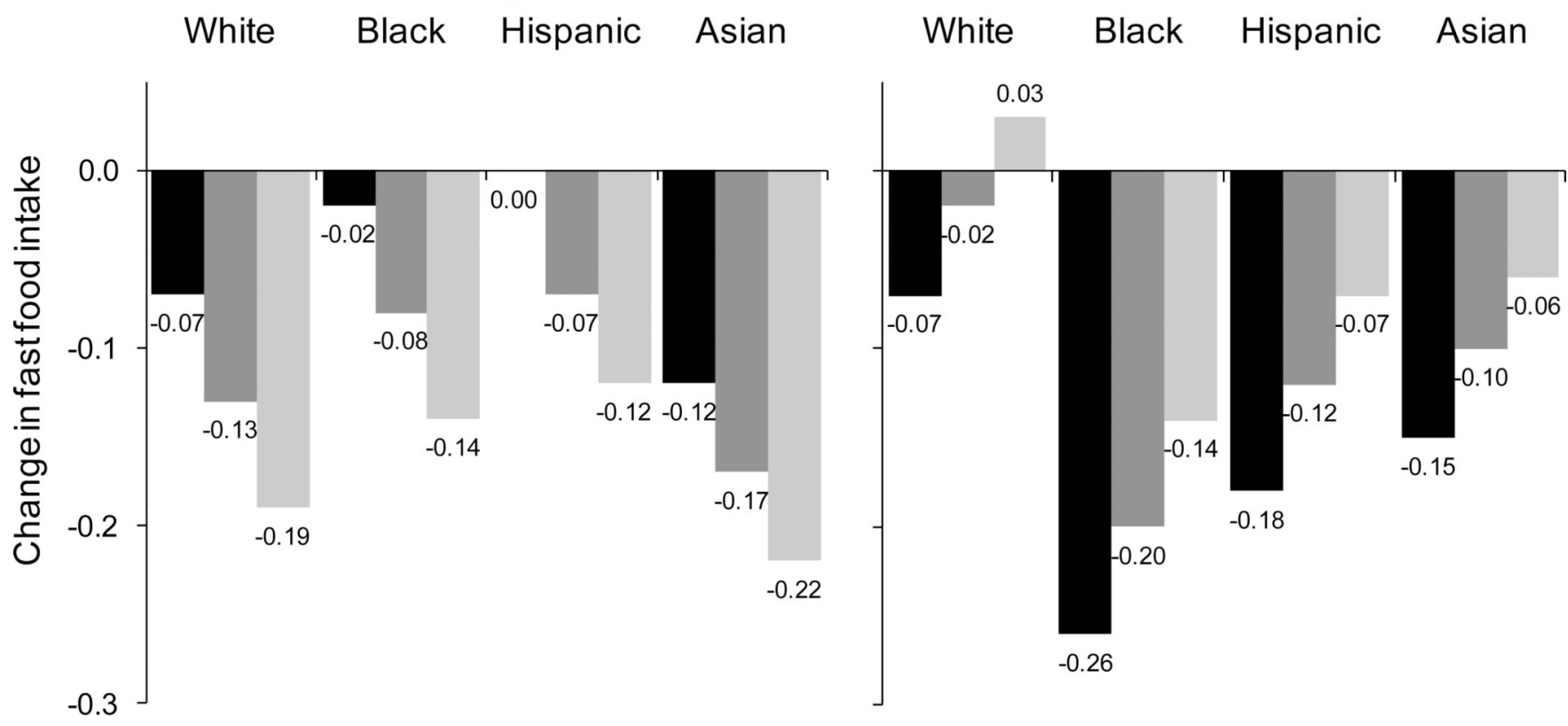

- Lo $\square$ Med $\square \mathrm{Hi}$

Figure 2.

Twenty percent increase in County-level prices of soda and burgers and associated decrease in number of individual-level fast food eating occasions by individual-level income and race, The National Longitudinal Study of Adolescent Health waves II (1996, 12-22 years) and III (2001, 18-28 years). 


\section{Table 1}

Baseline and Follow up descriptive statistics, respondents enrolled in The National Longitudinal Study of Adolescent Health waves II (1996, 12-22 years) and III (2001, 18-28 years) and their community characteristics at each time point

\begin{tabular}{|c|c|c|c|c|}
\hline \multirow[b]{2}{*}{ Variable } & \multicolumn{2}{|c|}{$\begin{array}{c}\text { Wave II } \\
N=14,604\end{array}$} & \multicolumn{2}{|c|}{$\begin{array}{c}\text { Wave III } \\
N=14,569\end{array}$} \\
\hline & Mean & SD & Mean & SD \\
\hline \multicolumn{5}{|l|}{ Individual-level Sociodemographics } \\
\hline Age & 16.24 & 1.64 & 21.98 & 1.78 \\
\hline Female $(\%)$ & 51.25 & 0.50 & 52.92 & 0.50 \\
\hline Black (\%) & 21.61 & 0.41 & 21.37 & 0.41 \\
\hline Hispanic (\%) & 16.65 & 0.37 & 16.23 & 0.37 \\
\hline Asian $(\%)$ & 6.77 & 0.25 & 6.62 & 0.25 \\
\hline Parent HS (\%) & 29.79 & 0.46 & 29.40 & 0.46 \\
\hline Parent Some College (\%) & 26.99 & 0.44 & 27.02 & 0.44 \\
\hline Parent College (\%) & 26.64 & 0.44 & 26.87 & 0.44 \\
\hline Income, per $\$ 1,000$ & 42.27 & 29.30 & 42.86 & 29.16 \\
\hline \multicolumn{5}{|l|}{ Individual-level outcome measure } \\
\hline Fast food meals per week & 2.21 & 1.79 & 2.47 & 2.09 \\
\hline \multicolumn{5}{|c|}{ Community-level exposures and control measures } \\
\hline County & \multicolumn{2}{|c|}{$\mathrm{N}=158$} & \multicolumn{2}{|c|}{$\mathrm{N}=363$} \\
\hline Price - soda ${ }^{*}$ & 1.36 & 0.21 & 1.20 & 0.11 \\
\hline Price-burger $^{*}$ & 2.33 & 0.28 & 2.28 & 0.20 \\
\hline Price-pizza ${ }^{*}$ & 8.34 & 0.82 & 9.51 & 0.74 \\
\hline Price-steak $^{*}$ & 5.89 & 0.97 & 7.22 & 0.99 \\
\hline Price-milk* & 1.45 & 0.18 & 1.88 & 0.28 \\
\hline Price-fried chicken ${ }^{*}$ & 2.23 & 0.21 & 2.58 & 0.26 \\
\hline Consumer Price Index $*$ & 1.86 & 0.06 & 1.78 & 0.07 \\
\hline Census Tract & \multicolumn{2}{|c|}{$\mathrm{N}=850$} & \multicolumn{2}{|c|}{$\mathrm{N}=2714$} \\
\hline Population Density ${ }^{\dagger}$ & 1278.48 & 2082.98 & 1394.18 & 2099.00 \\
\hline Population $<100 \%$ poverty $(\%)^{\dagger}$ & 0.15 & 0.12 & 0.15 & 0.12 \\
\hline Population College Educated $(\%)^{\dagger}$ & 0.23 & 0.13 & 0.22 & 0.16 \\
\hline Population White $(\%)^{\dagger}$ & 0.73 & 0.29 & 0.68 & 0.29 \\
\hline
\end{tabular}

* Council for Community and Economic Research. Price data are county-specific, real prices, in 2006 US dollars, for a 2-L bottle of soda ("soda"), a one-quarter pound hamburger purchased at a fast food restaurant ("burger"), a 13-in cheese pizza, regular crust, purchased away from home ("pizza"), a one-half gallon of whole milk ("whole milk"), $1 \mathrm{lb}$ US Department of Agriculture choice steak ("steak"), and fried chicken pieces, thigh and drumstick, purchased away from home ("fried chicken").

${ }^{\dagger}$ Census Tract Level (US Census) 


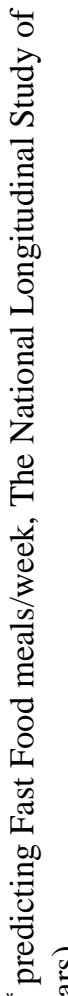

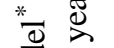

응

ఏ

.

: 일

录

$\stackrel{0}{0}$

.

ઘี

$\stackrel{9}{9}$

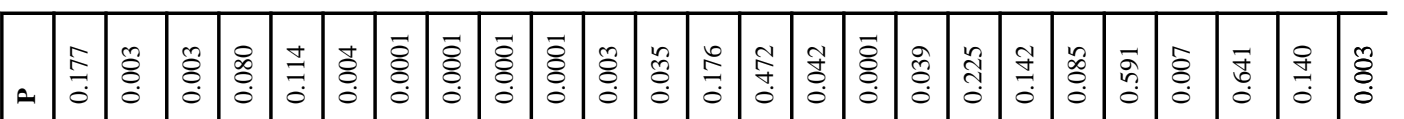

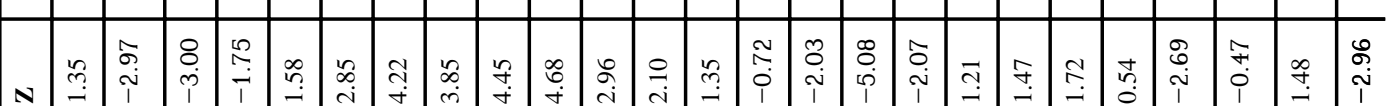

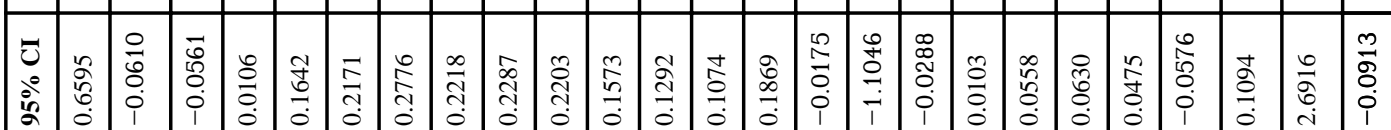

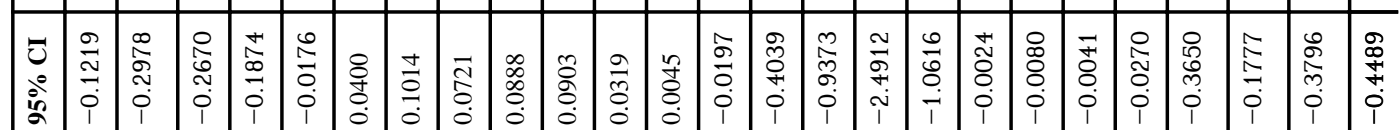

$\stackrel{\mathscr{E}}{\mathrm{\Xi}}$

ฮั

.

范

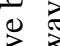

突

总

포

:

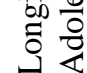

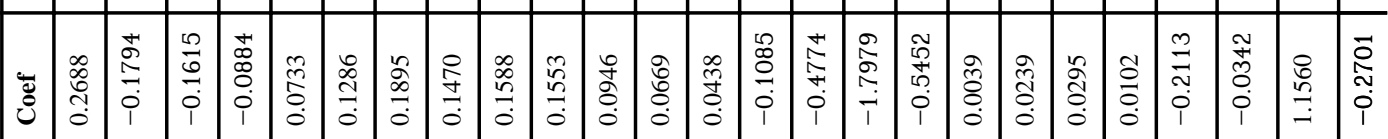

$$
\begin{array}{ll|l|l|l|l}
\hline & & & \\
\hline
\end{array}
$$

\begin{tabular}{|c|c|c|c|c|c|c|c|c|c|c|c|c|c|c|c|c|c|c|}
\hline & 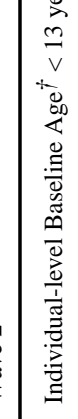 & 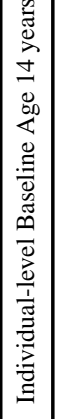 & 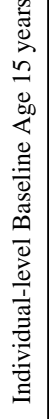 & 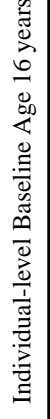 & 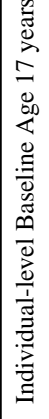 & 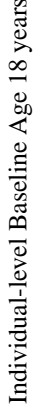 & 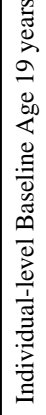 & 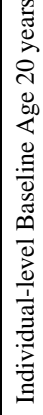 & 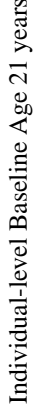 & 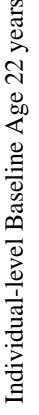 & 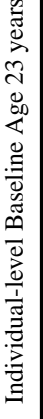 & 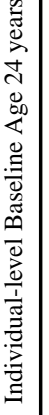 & (2) & & 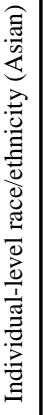 & & & 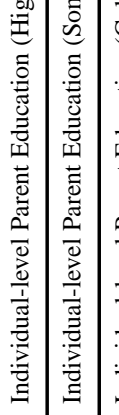 \\
\hline
\end{tabular}




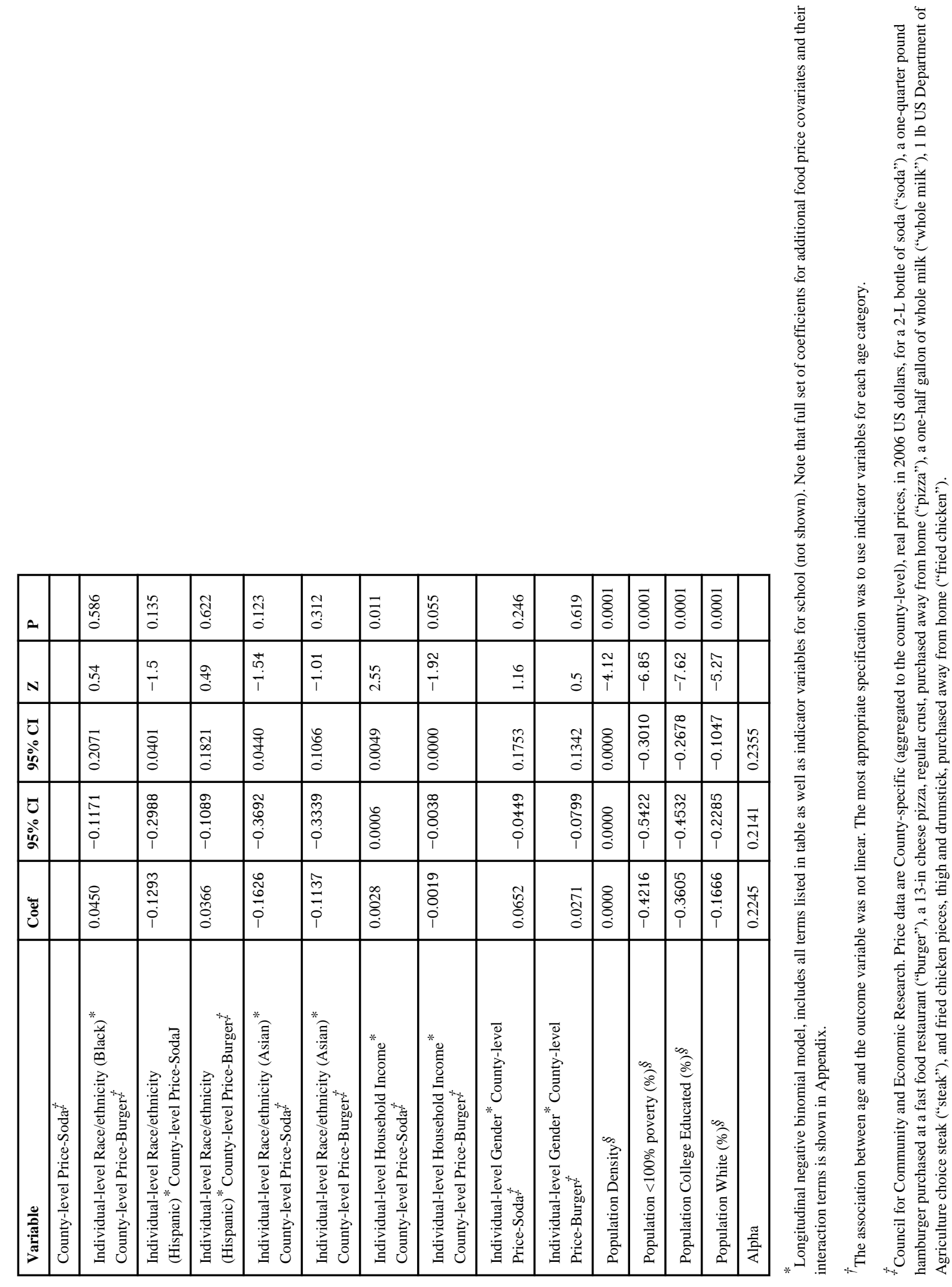


